Bert Peeters, The Australian National University, Australia

DOI: 10.17951/Ismll.2020.44.1.27-37

\title{
Language Makes a Difference: Breaking the Barrier of Shame
}

\begin{abstract}
This paper argues against the reification of shame and the use of Anglocentric jargon to explain what it entails. It shows how the Natural Semantic Metalanguage can be used to define shame and set it apart from related concepts in Australian Aboriginal English and in Bislama, an English creole spoken in Vanuatu.

Keywords: shame/ashamed, Natural Semantic Metalanguage, English, Australian Aboriginal English, Bislama
\end{abstract}

\section{Introduction}

Shame has been widely discussed in cross-cultural literature, not in the least by researchers who fail to understand they are operating with an English label they mistakenly believe to be translationally equivalent to the shame-related words used in the languacultures they observe. Kollareth, Fernandez-Dols, and Russell (2018) list a "plethora of studies" (p. 275) that suggest otherwise: shame-related words do not match across languages. They are profiled differently from one languaculture to another, often because they are embedded in networks of lexical items that do not match cross-linguistically either. In English, for instance, shame is related to but different from guilt and embarrassment. In many other languages, no comparable lexically marked contrast exists. There is either less or (sometimes much) more lexical differentiation than is found in English.

\section{Dangers to be avoided: reification and Anglocentricity}

The presumed translational equivalence of shame-related words has led to a substantial body of research in which shame - or rather the emotion referred to in English by means of the term shame - "has been theorized to be an everyday pancultural human emotional response to certain types of failure with important consequences" (Kollareth et al., 2018, p. 275). Shame has been afforded the status of a universal emotion, a phenomenon referred to as reification by those who feel

Bert Peeters, School of Literature, Languages and Linguistics, The Australian National University, Canberra, ACT 2600, Australia, Bert.Peeters@anu.edu.au, https://orcid.org/0000-0001-8422-4156 
this to be an unwarranted move. Wierzbicka (1999) and Levisen (2016) have been very outspoken in this respect:

The change in the meaning of the English shame should also be a warning to all those who are inclined to absolutize shame as a 'universal human emotion'. What 'shame'? The Shakespearian shame? The modern English shame? Or any one of a number of other emotions (such as, for example, the German Scham or the Polish wstyd), whose names are routinely translated into English as shame but which in fact do not mean the same? (Wierzbicka, 1999, pp. 111-112).

There is a tendency in the Anglo-international literature to reify 'shame' [as] a natural part of the human setup, and only subject to some minor variation across cultures. Consider for instance Epstein's classic work 'The Experience of Shame in Melanesia' (1984). This book is itself full of linguistic evidence against 'shame' as a universal emotion, such as the Tolai concept of warvirivir and the Busama concept of maya. Even though Epstein admits that some Melanesian terms are 'covering the emotional spectrum from shyness and mild embarrassment to something akin to guilt and morbid self-hatred' 1984: 37 [...], he insists that warvirivir and maya are expressions of 'shame' (Levisen, 2016, p. 50).

Reification also affects shame research involving European languages alone, as shown in the following excerpt from a paper by Krawczak (2018) who studied shame-related adjectives in English, French, and Polish:

The adjectives selected for the analysis in this study are instantiations of the lexical categories 'shame' and 'embarrassment', which, in turn, represent two distinct and yet closely related types of negative self-evaluative emotions, i.e., shame and embarrassment. Given that such emotions are dependent on a socio-culturally determined set of rules and expectations, it is only natural to assume that their conceptualization will vary across languages and cultures (p. 456).

Identifying lexical categories by means of English labels may be a handy shortcut, but it is also fraught with danger. 'Shame' and 'embarrassment' are at best lexical categories in English; there may be similar lexical categories in other languages, but they should not be identified by means of the same labels, as this would be a first step in the direction of the kind of reification we have to avoid if we want to be culturally sensitive.

Like most other research, research on shame is also characterized by a heavily Anglocentric jargon that may be illuminating to scholars but fails to provide a culturally sensitive description of what shame-related words mean to the speakers who use them. Krawczak's (2018) description is by no means unique in this respect. Her reliance on phrases such as "the core self", "negative self-evaluation", "loss of self-respect", "enduring diminished self-perception", "blemish in the self", is not very helpful to native speakers (cultural insiders) and foreigners (cultural outsiders) interested in acquiring a real sense of what shame/ashamed, French honte/honteux and Polish wstyd/zawstydzony are all about. The impression one has upon reading selected parts of Krawczak (2018) is that shame is something universal, a basic human category. This is of course not the case, as the author goes on to illustrate in the remainder of her otherwise very detailed investigation. 


\section{The NSM approach}

One way - perhaps the only way - to deal with the problems of reification and Anglocentric jargon is to use the so-called NSM approach. Named after the "Natural Semantic Metalanguage" painstakingly developed over several decades, initially by Polish-born linguist Anna Wierzbicka, who migrated to Australia in the early 1970s, then (as of the 1990s) by the most formidable linguistic tandem of the last 25 years, Wierzbicka and her erstwhile student Cliff Goddard, the NSM approach is arguably the most well-developed approach to cross-linguistic semantics on the contemporary linguistic scene. Ironically, Krawczak is aware of at least some of Wierzbicka's work on emotions; even so, there are no references to work published after 1999. Goddard, on the other hand, is not mentioned once. Unfortunately, Krawczak's summary of NSM-inspired findings relating to the concept of shame is contaminated with Anglocentric jargon and thus totally out of character with the general message scholars such as Wierzbicka and colleagues attempt to convey. And yet, there is some evidence that at least part of the message is getting through: in a slightly older text also dealing with shame (Krawczak, 2014, p. 443), we are reminded how important it is to avoid "'absolutizing' the concept as 'a universal human emotion' on the basis of its meaning in a given language, such as English".

For those who are unfamiliar with it, NSM can be characterized as a powerful descriptive tool created by linguists for linguists, but also for the world. It is a descriptive tool like no other. It is the tool that $17^{\text {th }}$ century philosophers such as Gottfried Leibniz, René Descartes, Blaise Pascal, Antoine Arnauld, John Locke and others dreamt of, but were unable to piece together. They were philosophers, after all, and no matter how well-intentioned they were, they did not have the linguistic know-how to make their dream a reality. Leibniz, in particular, has said some memorable things; little wonder he soon became and still is, historically speaking at least, Wierzbicka's greatest role model. Here are some significant quotes, translated by Wierzbicka herself, based on French originals published in 1903 (for the English versions, see e.g., Wierzbicka, 2011):

\footnotetext{
Although infinitely many concepts can be understood it is possible that only few can be understood in themselves. Because an infinite number can be constructed by combining a few elements. Indeed, it is not only possible but probable, because nature usually achieves as much as possible with as few elements as possible, that is to say, it usually operates in the simplest possible way.

If nothing could be understood in itself nothing at all could ever be understood. Because what can only be understood via something else can be understood only to the extent to which that other thing can be understood, and so on; accordingly, we can say that we have understood something only when we have broken it down into parts which can be understood in themselves (pp. 379-380).
}

Those "parts which can be understood in themselves" make up what Leibniz referred to as "the alphabet of human thoughts" (alphabetum cogitationum humanarum). After Leibniz's death, its compilation was lost sight of for centuries 
- only to be resumed in the 1960s, mainly thanks to the efforts of both Wierzbicka, whose first landmark publication came out in 1972 under the title Semantic Primitives, and Goddard. Apart from relying on their own investigations, they were able to put to the best possible use the extensive research carried out by linguists (colleagues as well as students), in Australia and elsewhere, on dozens of typologically and genetically unrelated languages from all corners of the world. In its most basic form, the NSM working hypothesis is beautifully summarized as follows (Wierzbicka, 2014, p. 33): "All languages share not only a lexical core but also a grammatical one, so at the heart of all languages there lies a mini-language, with as many realizations as there are languages" (p. 33).

The next question is: what is NSM good for? Wierzbicka has, once again, said it very beautifully (Wierzbicka, 2014, p.33): "The shared core of all languages provides a 'natural semantic metalanguage' for explaining meanings and ideas across languages and cultures". And because it is shared, it is deemed to be culturally neutral. As such, it provides an ideal tool for linguistic description that does not distort linguistic and cultural realities by imposing an Anglocentric (or any other ethnocentric) perspective. The NSM approach, which is inspired by that same desire to overcome ethnocentrism (and in particular Anglo bias) in linguistic analysis, is the paradigm in linguistic semantics that uses the Natural Semantic Metalanguage (the term is Goddard's) in its endeavour to explicate, i.e., make explicit, the meaning of culture-specific words and phrases. The technique used to this effect is known as 'reductive paraphrase'; it aims at reducing and ultimately removing cultural complexity by paraphrasing it into semantically simpler terms. The result is referred to as an explication. Explications such as those proposed below in $[\mathrm{A}]$ to $[\mathrm{F}]$ are fine-grained and, above all, non-Anglo-based descriptions that the English language as such is woefully inadequate to emulate in ways that are convincing to native speakers of other languages. Written in non-technical language, they are accessible to cultural insiders (those whose native language is English) and outsiders (all others) alike. Since, until compelling evidence to the contrary (or unless stated otherwise), nothing in an explication is non-universal, explications can be translated without deformation or bias into other languages (other NSMs), thereby making culturally specific terms universally intelligible.

In its purest form, NSM vocabulary is limited to 65 universal and easily crosstranslatable, semantically simple building blocks, known as semantic primes. After decades of empirically based research, it is believed the list is now nearly final. The primes have resisted all attempts at semantic decomposition into more basic elements and are therefore indefinable in terms that are semantically simpler than the primes themselves. The English exponents of the primes, grouped into meaningful categories, are listed in Table 1. Comparable tables for many other languages can be found on the NSM homepage at http://bit.ly/1XUoRRV. 
Table 1. Exponents of semantic primes in English

\begin{tabular}{|c|c|}
\hline I, YOU, SOMEONE, SOMETHING $\sim$ THING, PEOPLE, BODY & substantives \\
\hline KIND, PART & relational substantives \\
\hline THIS, THE SAME, OTHER $\sim$ ELSE & determiners \\
\hline ONE, TWO, SOME, ALL, MUCH MANY, LITTLE $\sim$ FEW & quantifiers \\
\hline GOOD, BAD & evaluators \\
\hline BIG, SMALL & descriptors \\
\hline KNOW, THINK, WANT, DON'T WANT, FEEL, SEE, HEAR & mental predicates \\
\hline SAY, WORDS, TRUE & speech \\
\hline DO, HAPPEN, MOVE & actions, events, movement \\
\hline BE (SOMEWHERE), THERE IS, BE (SOMEONE/SOMETHING) & location, existence, specification \\
\hline (IS) MINE & possession \\
\hline LIVE, DIE & life and death \\
\hline $\begin{array}{l}\text { WHEN } \sim \text { TIME, NOW, BEFORE, AFTER, A LONG TIME, } \\
\text { A SHORT TIME, FOR SOME TIME, MOMENT }\end{array}$ & time \\
\hline $\begin{array}{l}\text { WHERE } \sim \text { PLACE, HERE, ABOVE, BELOW, FAR, NEAR, SIDE, } \\
\text { INSIDE, TOUCH }\end{array}$ & place \\
\hline NOT, MAYBE, CAN, BECAUSE, IF & logical concepts \\
\hline VERY, MORE & augmentor, intensifier \\
\hline LIKE $\sim A S$ & similarity \\
\hline
\end{tabular}

Notes: • Exponents of primes can be polysemous, i.e., have other, additional meanings. $\bullet$ They may be words, bound morphemes, or phrasemes. - They can be formally, i.e., morphologically, complex. - They can have combinatorial variants or allolexes (indicated with $\sim$ ).

Each prime has its own "mini-grammar", its own combinatorial possibilities, that govern how it can combine with other elements of the metalanguage. NSM syntax is as universal as the primes, it is empirically validated, and it sets the rules for the combination of primes into the semantic components that make up an explication. Each of the primes has its own set of combinatorial properties. Charts that summarize these properties, or at least the most important of them, can also be found on the NSM homepage at http://bit.ly/1XUoRRV.

In summary, NSM thus consists of a maximally culture-neutral vocabulary of universal (or at least quasi-universal) and semantically simple building blocks held together by a syntax intended to be as universal as the building blocks themselves. Thanks to its universal (or at least quasi-universal) lexicon of primes and its universal (or at least quasi-universal) syntax, NSM is quite unlike any other descriptive tool used in linguistics. No other metalanguage has been developed for which there exist so many strictly isomorphic versions in languages 
other than English. No other metalanguage has been developed that allows for its outputs (referred to above as explications) to be so freely and (mostly) effortlessly translated into other NSMs. NSM is thus very much unlike ordinary languages, which at times raise considerable translation issues. No other metalanguage has been developed that can lay claim to being a genuine mini-language, as opposed to a terminology that does not have its own intuitively clear grammar. No other metalanguage has been developed that is unburdened with unnecessary (but necessarily alienating) associations with culturally tainted material from any language. Its English version can be used to explicate culturally specific material (including emotion terms) belonging to any other language, e.g., Japanese or Warlpiri, without adding an English spin to the explication - in exactly the same way as the Japanese or Warlpiri versions could be used to explicate culturally specific material belonging to English, without adding a Japanese or Warlpiri spin. For NSM practitioners, the so-called insider perspective is sacrosanct.

\section{Explications for ashamed and shame}

In the latest NSM literature, emotions are often explicated by embedding the corresponding explications in so-called semantic templates, a strategy that promotes comparability of related emotions, both intra- and cross-linguistically. Templates provide a structure that captures shared aspects, thereby making comparison of explications both easier and more effective. The use of templates allows for a more focussed comparison: it makes more sense to compare components (individual lines) of explications in meaningful clusters (or sections) than it does to go straight down to the smallest meaningful level, which is that of individual components.

Emotion templates, like most other templates, have been subject to amendment over time. To the best of my knowledge, Goddard (forthcoming) is the first to have made an explicit proposal for two very similar templates to be used side by side for emotions lexicalized as adjectives: one for be-constructions (e.g., be ashamed), the other one for feel-constructions (e.g. feel ashamed). Goddard proposes the following explication for the phrase "Someone $\mathrm{X}$ is ashamed":

(A) Someone $\mathrm{X}$ is ashamed =

a. this someone $\mathrm{X}$ thinks like this at this time:

"people can know something bad about me

if people know about it, they can't not think something bad about me I don't want this"

b. because of this, this someone feels something bad

c. like people often feel when they think like this

There is much less information in this explication than may be found in some treatments of conceptualizations of shame in the literature (e.g., Tissari, 2006). The main reason for this is that NSM explications aim to come up with some sort of an invariant or prototypical meaning that applies in a variety of settings. More 
importantly, explication (A) instantiates, albeit with a minimal change of he/she to this someone in section b., the first of Goddard's two templates (Figure 1).

Someone $\mathrm{X}$ is afraid, angry, ashamed, etc. ... (at this time)

a. this someone $X$ thinks like this at this time:

"---

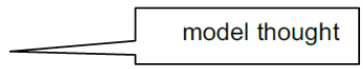

b. because of this, he/she feels something (very) good/bad

c. like people often feel when they think like this

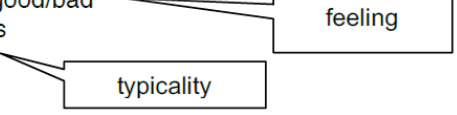

Figure 1: Semantic template for many English emotion adjectives with verb 'to be'

The template in Figure 1 has three main sections. Section a. attributes a "model thought" to the person experiencing the emotion. Section b. causally links this thought with a resulting feeling, which can be (very) good or (very) bad. Section c. ensures that the feeling attributed to the experiencer is what would be prototypically expected in connection with the model thought. "Overall, the idea is that being afraid, angry, or ashamed, or whatever, means being in a certain state of mind and because of that experiencing a certain kind of feeling, which is seen as typical of such a mental state" (Goddard, forthcoming).

The second template is shown in Figure 2, where the order of the components is reversed: the subject now feels something (very) good or (very) bad, like people often feel when they think in a certain way.

Someone $\mathrm{X}$ feels afraid, angry, ashamed, ... (at this time)

a. this someone $X$ feels something (very) good/bad at this time

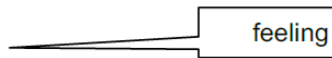

b. like people often feel when they think like this:

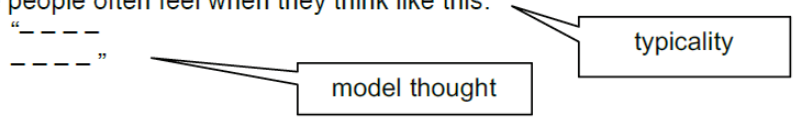

Figure 2: Semantic template for many English emotion adjectives with verb 'to feel'

Goddard (forthcoming) does not provide an explication for the phrase "Someone X feels ashamed". However, using the template in Figure 2, this phrase can be explicated as in (B) (where section b. has been split for increased symmetry with the template in Figure 1):

(B) Someone $\mathrm{X}$ feels ashamed $=$

a. this someone $\mathrm{X}$ feels something bad at this time

b. like people often feel when they think like this:

c. "people can know something bad about me if people know about it, they can't not think something bad about me I don't want this" 
Now, how should we account for the same phrase, with the same verb, but the noun shame (instead of the adjective ashamed)? There is a difference between to feel ashamed and to feel shame, which, in most varieties of English, is not reflected in a matching usage with the verb to be: for most speakers, the combination * to be shame is unacceptable. I suggest the following amended explications (amendments are indicated in italics):

(C) Someone $\mathrm{X}$ feels ashamed $=$

a. this someone $\mathrm{X}$ feels something bad at this time

b. like people often feel when they think like this:

c. "I did something, something happened

because of this, people can know something bad about me

if people know about it, they can't not think something bad about me I don't want this"

(D) Someone $\mathrm{X}$ feels shame $=$

a. his someone $\mathrm{X}$ feels something bad at this time

b. like people often feel when they think like this:

c. "people can know something bad about me, not because I did something, not because something happened

if people know about it, they can't not think something bad about me I don't want this"

Explication (C) now links feeling ashamed with a prior event, which could be something X did, or something that happened to him or her. Explication (D) links feeling shame with something that is more protracted, and not tied in with something that $\mathrm{X}$ did or something that happened to $\mathrm{X}$. A question that must remain unresolved for now is whether the amendments carried out in (C) also are to be carried out in (A).

\section{A brief look at Australian Aboriginal English and Bislama}

NSM explications such as the above offer unprecedented insights into the conceptualization of shame and shame-related words across the most diverse languacultures in terms cultural insiders and outsiders are equally able to understand. They promote comparability, while at the same time circumventing reification and ethnocentricity. Shame-related words have exercised the minds of several more or less experienced NSM scholars working on a host of different languages, including (but not limited to): Amharic (Ethiopia; Amberber, 2001), Arabic (Al Jallad, 2010), Chinese (Kornacki, 1995), Danish (Dineen, 1990), English (Wierzbicka, 1986; Harkins, 1990, Wierzbicka, 1992; Farese, 2016), French (Koselak, 2003), Iban (Borneo; Metom, 2000), Indonesian (Mulyadi, 1998), Japanese (Farese, 2016), Malay (Goddard, 1996, 1997), Maori (New Zealand; Harkins, 1996), and Polish (Koselak, 2005). Space limitations prevent me from providing further detail. Instead, what I would like to show is that interesting 
differences may appear even among varieties of English or in languages directly based on it. The examples that follow are taken from Australian Aboriginal English and from Bislama, an English-based creole spoken in Vanuatu. I hasten to add, though, that my interpretations are entirely based on the existing NSM literature; I have no first-hand knowledge of either Aboriginal English or Bislama.

Jean Harkins is one of the earliest NSM practitioners to have dealt with shamerelated concepts. Her special interest in the word shame in the English spoken by indigenous people living in the Alice Springs area of Central Australia has led her to propose two different explications. The second one (Harkins, 1996), presumably a condensed version of the first (Harkins, 1990), can be rewritten as in (E), which adopts the same template as explication (A).

(E) (Aboriginal English) Someone X (is) shame =

a. this someone $\mathrm{X}$ thinks like this at this time:

b. "I am here; this is bad something bad can happen because of this I don't want this"

c. because of this, this someone feels something bad like people often feel when they think like this

The caption used in explication (E) shows that the use of a copular verb is optional. The explication itself highlights in simple and readily cross-translatable words that shame in Aboriginal English is associated with the thought of being "here (near people or places that one should avoid, or where one doesn't know the rules)" (Harkins, 1990, p. 302), more so than with that of other people's ability to think something bad about the experiencer of Aboriginal English shame. The latter is not necessarily absent, but it does not appear to be part of the invariant meaning.

Levisen's (2016) explication of sem (i.e., shame) in Bislama can be rewritten as in (F), which adopts the same general template but changes the first-person perspective used by Levisen in the caption (i.e., mi sem; cf. English me shame) to the third-person, to bring it in line with the explications in (A) to (E).

(F) (Bislama) Man sem (cf. English someone shame) =

a. someone $\mathrm{X}$ thinks like this at this time:

b. "something happened in this place before because I did something in this place at that time other people here know about it now other people here can say something bad about me because of this I don't want this because of this I don't want to be in this place I want to be in another place for some time"

c. because of this, this someone feels something bad like people often feel when they think like this 
Explication (F) shows that Bislama mi sem appears to be closer to English I am (or feel) ashamed than to I feel shame: the Bislama speaker who says "Mi sem" refers to a prior event in a given place that caused sem, rather than to a more protracted emotion that may not be readily associable with a recent happening. It does so in terms that the average Bislama speaker can understand and that can be back-translated into Bislama, as Levisen (2016) himself has shown. It is information produced with the cultural insider (the Bislama speaker) in mind.

\section{Conclusion}

My conclusion will be brief. It is an answer to the question what exactly we stand to gain from the laborious and time-consuming process of producing explications such as those proposed in this short paper (and in the NSM literature at large). The answer to this question is straightforward. Most words and phrases in the thousands of languacultures of the world are culture-specific, some considerably more so than others. In the interest of successful cross-cultural communication, culture-specific material must be explicated to outsiders such as migrants, refugees, visitors and the like, and this must be done as much as possible with words they know, i.e. with universal and cross-translatable building blocks. Reification and ethnocentric jargon are hurdles we need to overcome. Cross-translatability and assessment of explications by cultural insiders, on the other hand, are the ultimate tests for the success of the NSM approach, a living example of what it is possible to achieve when rigorous and empirically based cross-semantic investigations are combined with a desire to produce outcomes that are useful not only for linguists, but for the world at large.

\section{References}

Al Jallad, N. (2010). The concept of "shame" in Arabic: Bilingual dictionaries and the challenge of defining culture-based emotions. Language Design, 12, 31-57.

Amberber, M. (2001). Testing emotional universals in Amharic. In J. Harkins, \& A. Wierzbicka (Eds.), Emotions in crosslinguistic perspective (pp. 39-72). Berlin: De Gruyter. DOI: 10.1515/9783110880168.35.

Dineen, A. (1990). "Shame/embarrassment" in English and Danish. Australian Journal of Linguistics, 10(2), 217-229. DOI: 10.1080/07268609008599442.

Epstein, A. L. (1984). The experience of shame in Melanesia. London: Royal Anthropological Institute.

Farese, G. M. (2016). The cultural semantics of the Japanese emotion terms "haji" and "hazukashii". New Voices in Japanese Studies, 8, 32-54. DOI: 10.21159/nvjs.08.02.

Goddard, C. (1996). The "social emotions" of Malay (Bahasa Melayu). Ethos, 24(3), 426-464. DOI: 10.1525/eth.1996.24.3.02a00020.

Goddard, C. (1997). Cultural values and "cultural scripts" of Malay (Bahasa Melayu). Journal of Pragmatics, 27(2), 183-201. DOI: 10.1016/S0378-2166(96)00032-X.

Goddard, C. (Forthcoming). Vocabulary of emotions and its development in English, German and other languages. In G. L. Schiewer, J. Altarriba, \& B. Chin Ng (Eds.), Handbook of language and emotion. Berlin: De Gruyter. 
Harkins, J. (1990). Shame and shyness in the Aboriginal classroom: A case for "practical semantics". Australian Journal of Linguistics, 10(2), 293-306. DOI: 10.1080/07268609008599445.

Harkins, J. (1996). Linguistic and cultural differences in concepts of shame. In D. Parker, R. Dalziell, \& I. R. Wright (Eds.), Shame and the modern self (pp. 84-96). Melbourne: Australian Scholarly Publishing.

Kaufman, G. (1996). The psychology of shame: Theory and treatment of shame-based syndromes. New York: Springer.

Kollareth, D., Fernandez-Dols, J.-M., \& Russell, J. A. (2018). Shame as a culture-specific emotion concept. Journal of Cognition and Culture, 18(3-4), 274-292. DOI: 10.1163/15685373-12340031.

Kornacki, P. (1995). Heart \& face: Semantics of Chinese emotion concepts (Doctoral dissertation thesis, Australian National University, Canberra, Australien).

Koselak, A. (2003). Approche sémantique du concept de honte. Pratiques, 117-118, 51-76. DOI: 10.3406/prati.2003.1995.

Koselak, A. (2005). « Quelle honte! Ale wstyd! » Observations sémantiques sur quelques emplois de «honte » et de «wstyd» ["Quelle honte! Ale wstyd!" Semantic observations on a few uses of honte et wstyd]. Roczniki Humanistyczne, 53(5), 105-124.

Krawczak, K. (2014). Shame, embarrassment and guilt: Corpus evidence for the cross-cultural structure of social emotions. Poznań Studies in Contemporary Linguistics, 50, 441-475. DOI:10.1515/psicl-2014-0023.

Krawczak, K. (2018). Reconstructing social emotions across languages and cultures: A multifactorial account of the adjectival profiling of shame in English, French, and Polish. Review of Cognitive Linguistics, 16, 455-493. DOI: 10.1075/rcl.00018.kra.

Levisen, C. (2016). Postcolonial lexicography: Defining creole emotion words with the Natural Semantic Metalanguage. Cahiers de lexicologie, 109, 35-60. DOI: 10.15122/ isbn.978-2-406-06861-7.p.0035.

Metom, L. (2000). An application and interpretation of Iban emotion concepts of shame/shyness, anger and apology using the Natural Semantic Metalanguage and concrete/abstract cultural continuum. In M. Leigh (Ed.), Borneo 2000: Ethnicity, culture and society. Proceedings of the Sixth Biennial Borneo Research Conference (pp. 250-277). Kuching: Universiti Malaysia Sarawak.

Mulyadi (1998). Makna “malu” dalam Bahasa Indonesia (Kajian "wacana kebudayaan") [Shamerelated meanings in Bahasa Indonesia (A study in "cultural discourse")]. Linguistika, 6, 46-57.

Tissari, H. (2006). Conceptualizing shame: Investigating uses of the English word shame, 14181991. In R. W. McConchie, O. Timofeeva, H. Tissari, \& T. Säily (Eds.), Selected proceedings of the 2005 Symposium on New Approaches in English Historical Lexis (HEL-LEX) (pp. 143154). Somerville: Cascadilla Proceedings Project.

Wierzbicka, A. (1972). Semantic primitives. Frankfurt am Main: Athenäum.

Wierzbicka, A. (1986). Human emotions: Universal or culture-specific? American Anthropologist, 88(3), 584-594. DOI: 10.1525/aa.1986.88.3.02a00030.

Wierzbicka, A. (1992). Semantics, culture, and cognition: Universal human concepts in culturespecific configurations. New York: Oxford University Press.

Wierzbicka, A. (1999). Emotions across languages and cultures: Diversity and universals. Cambridge: Cambridge University Press.

Wierzbicka, A. (2011). Common language of all people: The innate language of thought. Problems of information transmission, 47(4), 378-397. DOI: 10.1134/S0032946011040065.

Wierzbicka, A. (2014). Imprisoned in English: The hazards of English as a default language. New York: Oxford University Press. 